\title{
A Research Review of China's Teacher Education Integration
}

\author{
Yuewen LI \\ College of Pre-school Education, \\ Chongqing University of Education, \\ Nan'an, Chongqing 400067
}

\begin{abstract}
At the beginning of the 21th century, the integration of teacher education has become a hot issue in the studies of China's teacher education. In this paper, a discussion is conducted from the change from normal education to teacher education, the intension of teacher education integration, and the exploration on China's teacher education integration, and then the existing problems are analyzed, and finally the future research direction is raised.
\end{abstract}

Keywords: Teacher Education; Pre-service and In-service; Integration

\section{Introduction}

In 2001, the concept of "teacher education" was first used in the Decision of the State Council on the Elementary Education Reform and Development to replace "normal education" which has been in long-term use. In 2002, the Suggestions of the Ministry of Education about the Reform and Development of Teacher Education during the Period of the "15th Five-year Plan" showed "under the guidance of the life-long educational ideas, the integration of pre-service and in-service training of teachers is linked with the training giving top priority to existing normal colleges and inviting other types of colleges to join, so as to reflect a life-long, open teacher education system". Thus, the transition from normal education to teacher education started in China.

\section{The presentation of the problems in the integration of teacher education}

\subsection{The disadvantages of normal education}

Normal education first appeared in Europe. A normal education system was established in China from the late 19th century to the early 20th century. After more than a century of development, a large number of teachers were provided by normal education for all sorts of schools, thus making a huge contribution to education development. However, the disadvantages of normal education were increasingly apparent.

\subsubsection{Divorcement between curriculum provision} and post-service education

People think that the development goals in all pre-service and post-service phases were not unified in normal education on the basis of teachers' major development law; an overall plan was unavailable for all courses, and pre-service and post-service divorce with each other; another drawback in normal education's curriculum provision lied in the absence of normal educational characteristics and the major course system was similar to that of comprehensive universities. Studies found that normal education as a period of teacher training was regarded as a pre-service propaedeutic education for teachers, but it was also a terminal education not considering the link with post-service education.

2.1.2 Divorcement between education theory and practice

The separation of theory and practice is another problem of normal education. Education is complex and changeful, and therefore, the real understanding and internalization of education 
theory are impossible for normal college students to only rely on memorization and speculative exploration. Once the actual conditions of schools were deeply known by the students, education practice couldn't be instructed by these "universal" education theories, and finally, students had to seek a professional development through their own exploration or by consulting aged teachers. Thus, the divorcement between education theory and practice is caused by the mutually-uncorrelated theory and practice evolution process.

2.1.3 Fiercely independent education institutions An effective communication is absent between all levels of school resources. Institutions of higher learning, all kinds and levels of basic education schools, education colleges, and teacher continuing education schools are representatives of various school resources, and they play their role in the professional development chain of teachers, but these resources have not been effectively utilized yet. Meanwhile, these schools focus on independent education tasks and do not have a mutual communication or their communication is not enough. This phenomenon is especially apparent in universities and elementary and middle schools.

\subsection{From normal education to teacher education}

\subsubsection{The origin of teacher education}

In the 1970s, closed normal colleges were abolished successively in the European and American developed countries and an open modern teacher education training system fitting the era of knowledge economy was established, aiming to adapt to the rapid development of science and technology and cope with the increasingly fierce international competition. After undergraduate courses are completed, education course and training can be chosen based on the self-intensions, so as to accomplish the cultivation of teachers. At the end of the 20th century, the layout structure of normal schools was adjusted in China, and thus, the transition process of normal education was started.

2.2.2 The inherent requirement of teacher education lies in integration

Integration is an essential feature of teacher education, requiring the pre-service and post-service education to be linked and the teaching research and practice to be integrated. Supports for the whole process of teachers' career are highlighted, and then knowledge communication and creation can be realized at the same time. Furthermore, teachers must learn in their whole life and constantly update ideas, adjust the value orientation, and acquire new knowledge and skills, for adapting to the needs of the changing educational environment.

\section{Study on the intension of teacher education integration}

\subsection{Scientifically understanding the intension of teachers' pre-service and post-service education integration}

The teacher education integration in China is implemented mainly for the problems such as the separation of teachers' pre-service and post-service education and teaching content overlaps. The basic idea is "all growth stages of teachers are considered as a whole to link pre-service and post-service training together, making them integrated".

3.1.1 Basis

What is the basis to construct an overall plan for teacher education? Aizhu ZHANG thinks that the contents for teacher education integration are necessarily planned according to the teaching profession life cycle research framework raised by Huberman, et al.

\subsubsection{Goal}

Teacher education is a unified process and should serve the basic education and implement the requirements of quality-oriented education according to the national educational policy and the literacy structure of teachers. An overall goal for the quality of teachers must be constructed to 
guide the life-long education of teachers. Eventually, the pre-service and post-service training of teachers can be developed around the overall goal.

\subsubsection{Contents}

The integration of teacher education is a systematic project, including the all-round, multi-level integration of education thought, education management and organization, education content, education methods and so on. The change from the traditional normal education concept to the modern teacher education concept is the forerunner; the construction of integrated teacher education system is the key point; the reform of educational contents and methods promotes the integration of teacher education to be fully implemented.

\subsubsection{Courses}

In order to prevent the repetition and omissions of course setting, two principles are raised by Xiaojie LUO: courses are necessarily set by in-service teachers with vision to link with the curriculum provision of higher education; the sequent learning needs of students are necessarily considered by in-service teachers and the courses are better set according to the characteristics of all growth phases of in-service teachers to ensure the continuity of the curriculum provision in the post-service phases.

\subsubsection{Management}

To implement the integration of teacher education, the separated tasks of all departments are necessarily changed. From the national level, teacher education is designed, in which a scientific integrated teacher education system is established to achieve powerful guidance, standards, motivation, and other functions; a linkage mechanism for the departments related to teacher education is established, to promote government management departments (e.g. personnel bureau and education bureau), teacher education departments (e.g. higher normal colleges and teachers continuing education schools), and primary and secondary schools and kindergartens to cooperate in terms of teacher education and realize the integration of teacher education management.

\subsection{Exploration on the integration of teacher education}

In 1999, Several Suggestions on the Layout Structure Adjustment of Normal Colleges and Universities were promulgated by the Ministry of Education, showing "it is necessary to strategically restructure normal education resources, vigorously enlarge higher teacher education, steadily reduce secondary normal education, actively push forward the merger between municipal education colleges and local normal colleges based on the actual conditions, and construct a group of normal colleges or normal specialized postsecondary colleges to undertake the tasks of training primary and secondary school teachers."

3.2.1 Teacher education reform practice in institutions of higher learning

Institutions of higher learning are the main forces of the integration of teacher education. Throughout the practice of these schools, the focus is mainly on two levels - school and departments. The exploration at the school level involves a wide range and is systemic and consistent. For example, the integration of teacher education is overall designed by Sichuan Normal University from the school level, and its main contents are as follows: (1) to promote the construction of teaching management system; (2) to highlight the role of the courses in teacher education; (3) to carry out the activities of "access to new courses"; (4) to implement an "assistant tutor system"; (5) to strengthen the professional skills of normal college and university students.

\subsubsection{Cooperation practice}

The essence of the integration of teacher education is to break the previously closed teacher training method and form an open teacher education, in which more elements are involved, overall planning competence is stronger, and values are bigger. Furthermore, the cooperation 
of government's educational management departments and schools with teachers, and the cooperation among institutions of higher learning, teacher continuing education schools, primary and secondary schools, and kindergartens have been made in practice.

\subsubsection{Other reform practice}

In the above practice, explorations on the integration of basic education and teacher education are mainly involved, and explorations on cadres training and higher teacher education have been also conducted.

\section{CONCLUSIONS}

The different aspects of the teacher education integration in China are reviewed, and the study progress of teacher education integration is concluded. In the following, the main problems and future emphases are briefly analyzed and studied.

\subsection{Insufficient study operability and pertinence}

The studies on the integration of teacher education are conducted around the origin, intension, and practice of the integration, and many study achievements have been obtained. These results are more inclined to the concept level and theories, and enlighten people from ideas, but to implement these ideas in practical actions is difficult from the operational level. Moreover, in these studies, the problems in each detail are analyzed and explored not deeply, and also the problem pertinence is unclear.

\subsection{Scattered study forces and achieving several results in key issues}

The studies are mainly centered at the necessity of teacher education's transformation and the connection of teachers' pre-service and post-service training. Practice is mostly limited to the partial change of the departments of colleges and the practice exploration of some institutions of higher learning. In fact, the integration of teacher education is a systematic project and touches upon every aspect of teacher education, and thus, governmental departments are required to provide system construction and unified deployment; the training of college and university teachers is required to change comprehensively; the construction of teacher continuing education school and the cooperation of primary and secondary schools and kindergarten are required to carry out. However, such a systematic, grand exploration remains to be not enough, and further studies are still necessary.

\subsection{Not enough stressed teacher education integration in institutions of higher learning}

The teacher education integration in institutions of higher learning is a due task of the national teacher education integration. Throughout research literatures, only one study is related to the integration of higher vocational teachers training. However, the teacher education integration in institutions of higher learning is an issue that should never be ignored. For example, most teachers in institutions of higher learning do not graduate from normal education; the systematicness and effectiveness of inductive education are necessary to further explore; teacher improvement and training need a systemic plan and continuous training.

\section{References}

[1] Xiaojie LUO. Full-process Normal Education Concept - the Integration of Teachers' Pre-service and In-service Education $[\mathrm{J}]$. Higher Normal Education Research, 2002 (4).

[2] Chengfeng ZHANG. Exploration and Practice of Pre-service and In-service Integrated Training Model of Elementary School's Chinese Language Teacher [J]. Continuing education study, 2011, (6).

[3] Jubin ZHANG. Exploration on Music Teachers' Education Theory and Practice 
integration $[\mathrm{J}]$. Journal of Continuing Education Research, 2012, (8).

[4] Hongmei WANG, huasue DU XIU. Study on the Teachers' Education Integration Strategies in Southern Regions [J]. Journal of Jiangsu Teachers University of Technology, 2010, (7).
[5] Hong LI, Xianmei YANG. Study on the Pre-service and In-service Integrated Training of Higher Vocational Teachers in Theory Application Ability [J]. Journal of Continuing Education Research, 2012, (8). 